\title{
Standardization of Processes Applying CMMI Best Practices
}

\author{
Vítor Serrano $^{1}$, Anabela Tereso ${ }^{1}$, Pedro Ribeiro ${ }^{2}$ and Miguel Brito ${ }^{2}$ \\ ${ }^{1}$ Department of Production and Systems Engineering \\ ${ }^{2}$ Department of Information Systems \\ University of Minho, 4800-058 Guimarães, Portugal \\ pg16496@alunos.uminho.pt, anabelat@dps.uminho.pt, pmgar@dsi.uminho.pt, \\ mab@dsi.uminho.pt
}

\begin{abstract}
Capability Maturity Model Integration (CMMI) is a set of practices that can be applied in companies in order to improve processes. The goal of this work was to understand the barriers in implementing CMMI and improve processes following the model. The study was conducted in a company in the North of Portugal, following three steps: (1) diagnosing the company (2) opinion gathering through questionnaires and (3) reimplementation of CMMI. The analysis of the questionnaires indicated that implementing CMMI is problematical due to bureaucracy and lack of detailed protocols. Based on the difficulties encountered we developed a detailed documentation with standard processes where the employer has a more prominent role in controlling the processes. The adapted CMMI was then re-introduced in the same company. Finally, linking perceptions and results from the reimplementation, we consider fundamental a good use of CMMI to ensure efficient production.
\end{abstract}

Keywords: CMM (Capability Maturity Model), CMMI (Capability Maturity Model Integration), Reimplementation, Process Improvement.

\section{Introduction}

The current study aimed to implement CMMI in a technical department of a company in the North of Portugal.

Nowadays, most companies have great care in defining a set of suitable practices for the successful development of their products. It is assumed that a company must have a set of defined and standardized processes that organize the work done by their employees. However, bustle in the industrial world leads sometimes to a lesser concern when developing a product, without deepening all its essential aspects. This may lead to higher costs and to customer dissatisfaction.

The study was designed to understand why the CMM project implemented on the past in the company failed and how could the model be improved.

Companies aim to complete the tasks that meet the customers' needs, within time and at a lowest possible cost [1]. Proper project management is central to achieve the 
aforementioned goals [2]. That is the reason why good practice models focus their study on improving the project management area.

Regarding process management, CMMI seeks that a company achieves high maturity in specific subjects. This model goes beyond a set of mandatory rules and looks for approaches to improve the development and maintenance of the product [3]. The practices are applied throughout the life cycle of the product, from initial design until delivery to the final consumer [2].

According to current literature, the use of CMMI processes has several advantages. Sun and Liu emphasized three benefits: (1) description of processes' requirements, (2) presence of an integration method with prioritization of those requirements and (3) continuous improvement practice [4]. The CMMI is a methodology that is difficult to apply to organizations because it is a process that requires an involvement of the entire organization [5]. However, as pointed out by Huang and Han, CMMI creates good practices within a company, but the model implementation is not user friendly [6]. When implementing CMMI, managers are faced with the difficulty of defining the priority areas. Applying a formal CMMI model requires a great effort because it can be complex and time-consuming.

A crucial step on the path of business success is achieving maturity. In this sense, there are maturity levels which correspond to process areas ${ }^{1}$ [7]. In line with this approach, quality is achieved through continuous improvement of processes.

\section{Method}

To better understand the action-research method used on this study we will start by explaining its fundamental characteristics: definition, key principles, types, tools and the role of the researcher. We will then describe the stages of the experimental research done: 'Diagnosing the company', 'Opinion gathering through questionnaires' and 'CMMI methodology reimplementation'.

\subsection{Action-Research}

The action-research method implies learning throughout its application. After identifying a problem, multidisciplinary teams should be created to analyze the problem. From this analysis, an action plan is designed that will be implemented later. Actions are taken after a team analysis and followed by an evaluation of the outcome. These cycles are repeated until a solution is reached (Fig. 1). These methods entail several advantages for the companies. A major advantage is the increase on team motivation due to greater involvement in problem solving. Furthermore, solutions are easy to implement since they meet the suggestions provided by all [8].

\footnotetext{
1 "Process area: A cluster of related practices in an area that, when implemented collectively, satisfies a set of goals considered important for making improvement in that area. (CMMi v1.3 glossary)"
} 


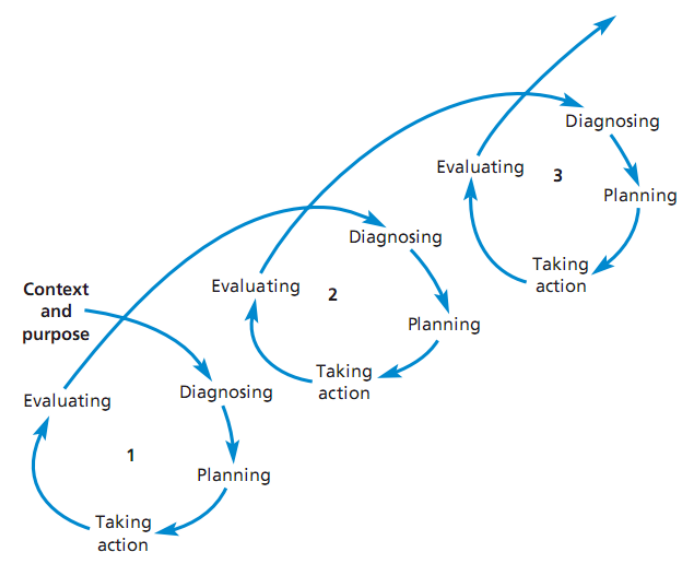

Fig. 1. The action research spiral [8]

\subsection{Stages of the Experimental Research}

The action-research method was split in three stages. During the first stage we diagnosed the company by verifying the processes description and how the processes are being executed. On the second stage, we administer two questionnaires. The first questionnaire was administered to all employees of the department under study that worked with CMM (Appendix 1). The main goal of this questionnaire was to detect and understand the major drawbacks of CMM implementation. With this data we could identify the steps that need improvement. The second questionnaire was completed by Portuguese companies licensed by SEI (Software Engineering Institute). With this data we wanted to collect the opinion about the methodology, its implementation and its acceptance.

The third stage consisted in executing an improved version of CMMI that should be a useful tool and an asset to the department under consideration.

First Stage - Diagnosing the Company. To realize the current situation of the company we examined the existing documents. The entire structure follows the CMM applied in the past. The data regarding the processes was spread and organized differently in various areas. This required different strategies to collect the information. The strategy plan took in consideration the following:

- What is the department process?

- What are the requirements for the process?

- How to manage the software?

- How to manage the resources?

- How to manage a project?

Flowcharts were created for each of the above points, in order to achieve better visualization. So this way, we seek to identify possible improvements and we were 
able to verify the overall operation of the process in the department (inputs, department functions and outputs).

Second Stage - Administering the questionnaires. In order to understand why the CMM implementation in the past failed, we considered fundamental to understand the team barriers for the methodology execution. For that purpose, we administered a questionnaire to nine team workers with past experience in CMM. The questionnaire had four questions (defined after a brainstorm with several team workers) and its main goal was to recognize their insights about the methodology.

Another questionnaire (with five questions) was sent to ten companies by email after phone contact.

All the answers were analyzed and taken into consideration for CMMI reimplementation.

\section{Third Stage - Reimplementation of CMMI Methodology}

This last stage was used to develop and apply new procedures. All the new procedures are being applied, according to the company plan, with the goal to facilitate the work of the employees and to ensure the best practices of CMMI. A group with three staff members was organized to develop new procedures. Regular meetings were held between this group, with occasional collaboration of the remaining team. These procedures were then introduced and evaluated, and their effectiveness was constantly checked through regular meetings with the employees involved. These regular checkpoints contributed to a sustained improvement of the new procedures.

\section{Results}

\subsection{Questionnaire to Company Employees (Questionnaire 1)}

In the company under study, previous CMM implementations were not a success. In some projects, the CMM was not even applied. Therefore it was necessary to identify the problems of those previous implementations in order to search for the reasons behind the failure.

A simple questionnaire with four questions was presented to the nine employees (eight male and one female) involved in previous CMM implementation, with ages around thirty-eight years old.

The answers given allowed concluding that the most appreciated feature of CMM was the use of common terminology (Fig. 2). However the most significant aspect mentioned was the reduction of errors and redundancies.

On the other hand, the worst aspects were the insensitivity about the organizational context and the amount of bureaucracy needed. 


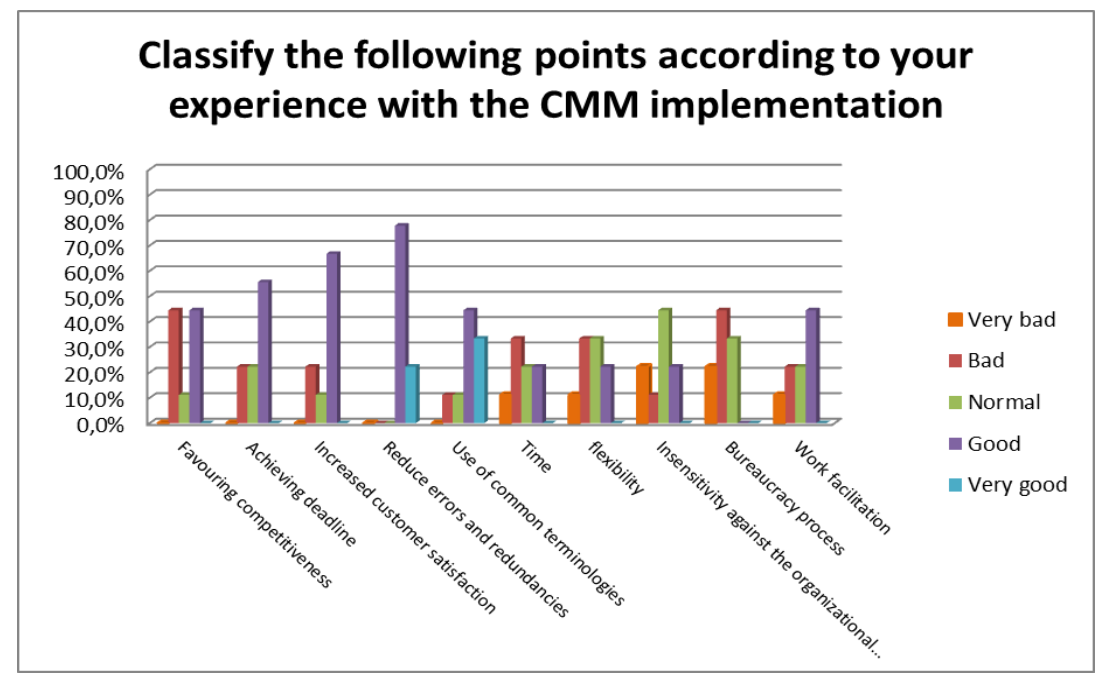

Fig. 2. Answer to question nr 1

The main conclusion about this first question (Fig. 2) is that employees feel CMM as very bureaucratic and hard to implement. However several positive aspects were also found. So, it is fair to conclude that people are open to the application of CMM provided it does not lead to an increased workload. Therefore solutions should be focusing on creating easy implementation processes.

Considering the second question, "What are the main positive aspects identified in project development before the implementation of CMM?", all answers given by this study participants (table 1) shown that before CMM, there was no existing standard, forcing people to find unrelated and creative ways for controlling their projects.

Table 1. Answers given to question 2

\begin{tabular}{|c|l|}
\hline Respondents & \multicolumn{1}{|c|}{ Answers given } \\
\hline 1 & $\begin{array}{l}\text { Greater documental freedom. More time to achieve the task. } \\
\text { Better alignment with the project Time To Market (TTM), } \\
\text { since over time changes do not require re-documenting all the } \\
\text { planning in the department as with CMM. } \\
\text { Existence of well-defined systematic procedures. } \\
\text { When there are no standards we cannot talk about positive } \\
\text { aspects of projects development. }\end{array}$ \\
\hline 2 & $\begin{array}{l}\text { Project management with less bureaucracy. Greater } \\
\text { flexibility. }\end{array}$ \\
\hline 3 & $\begin{array}{l}\text { Individual creativity, lack of systematization promotes } \\
\text { unexpected solutions, some of them innovative. }\end{array}$ \\
\hline 4 & $\begin{array}{l}\text { Less bureaucracy! Unnecessary standards use! } \\
\text { Did not answer. }\end{array}$ \\
\hline 5 & $\begin{array}{l}\text { Fast execution. } \\
\text { Less time spent on bureaucratic processes. }\end{array}$ \\
\hline 6 & Documents controlling activities and problems follow-up. \\
\hline 7 &
\end{tabular}


The answers to the question of used standards, considering documentation, in projects development before CMM, can be analysed in Table 2 .

Table 2. Question 3 results

\begin{tabular}{|l|l|}
\hline Respondents & \multicolumn{1}{|c|}{ Answers given } \\
\hline 1 & $\begin{array}{l}\text { TTM time schedule used in project management - } \\
\text { internal checklist - department standards checklist. }\end{array}$ \\
\hline 2 & $\begin{array}{l}\text { For our internal work processes, we could act without } \\
\text { being owners, only in a few existing processes. }\end{array}$ \\
\hline 3 & $\begin{array}{l}\text { Non existing standards, each one creating one's } \\
\text { supporting documents to project planning. }\end{array}$ \\
\hline 4 & $\begin{array}{l}\text { Open point list, cost planning, test matrix. } \\
\text { No standards documentation, each one organizing and } \\
\text { documenting the activities according to the demands. }\end{array}$ \\
\hline 5 & \begin{tabular}{l} 
No memory. \\
No answer. \\
\hline 6
\end{tabular} \\
\hline 7 & $\begin{array}{l}\text { Before CMM we used: test matrix, test coverage and } \\
\text { open point list. }\end{array}$ \\
\hline 9 & A few, the ones we created. \\
\hline
\end{tabular}

According to this question there was no standard documentation for project management. We emphasize answer 9 (Table 2) "A few, the ones we created". This statement shows the existing reality, where each one developed his own procedure for project management.

Finally, Table 3 shows the given answers to the questionnaire's last question, "What changes/suggestions would you like to include regarding reimplementation improvement of CMM processes?".

Table 3. Question 4 results

\begin{tabular}{|c|c|}
\hline Respondents & Answers given \\
\hline 1 & $\begin{array}{l}\text { Simplicity of processes. Whenever possible, gather as } \\
\text { much information in the same document serving several } \\
\text { requirements. Use a web platform to simplify and have } \\
\text { faster documentation. }\end{array}$ \\
\hline 2 & $\begin{array}{l}\text { Re-evaluation of all documents and procedures to help } \\
\text { simplifying and decreasing documents. Less bureaucratic } \\
\text { processes without confirmed utility. }\end{array}$ \\
\hline 3 & $\begin{array}{l}\text { Less papers and bureaucracy. Implementation should be } \\
\text { supported by computer tools. }\end{array}$ \\
\hline 4 & $\begin{array}{l}\text { Fewer documents to fill in and less repeatability of } \\
\text { information in different documents. }\end{array}$ \\
\hline 5 & Automatic and standard processes. \\
\hline 6 & $\begin{array}{l}\text { Greater participation and commitment of all partners in } \\
\text { reimplementation. Their participation in developing and } \\
\text { reformulating standard tools and procedures to be used in } \\
\text { the process is essential to their improvement. }\end{array}$ \\
\hline
\end{tabular}




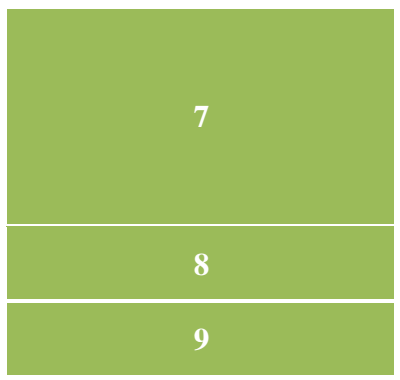

Tools improvement to control test system! Using these tools should not be so bureaucratic! Some reviews should be done only once, not constantly (ex: When a Process Alignment and Verification (PAV) comes out, a new review should not be done till a new PAV appears). Creation of a specific TEAM to CMM.

Simple documentation process; controlling activities and trusted registration.

Evaluation of only strictly necessary documents; possibility to merge documents; create a CMM simplex.

The answers to this last question show the need of simplifying documents and processes. These suggestions will meet the results of the third question, in which bureaucracy was shown as to be a negative aspect of CMM. Linking these two questions, it seems that these are the key points for success in the reimplementation of CMMI.

\subsection{Companies Questionnaire (Questionnaire 2)}

A second questionnaire (online) was applied in order to analyze the implementation of CMMI in Portuguese companies certified by SEI. A questionnaire consisting of five multiple choice questions was prepared and sent to ten companies. However, this activity has not completely successful because only four companies responded within the time needed to complete this project. But this questionnaire should be used for future projects in order to complete the intended analysis.

Nevertheless, we have decided to analyze the four companies' answers, followed by presentation and results discussion.

The first question on the implementation of CMMI, 50\% of the sample shows that it was considered difficult, $25 \%$ found it easy and $25 \%$ said that it was a normal process (Fig. 3).

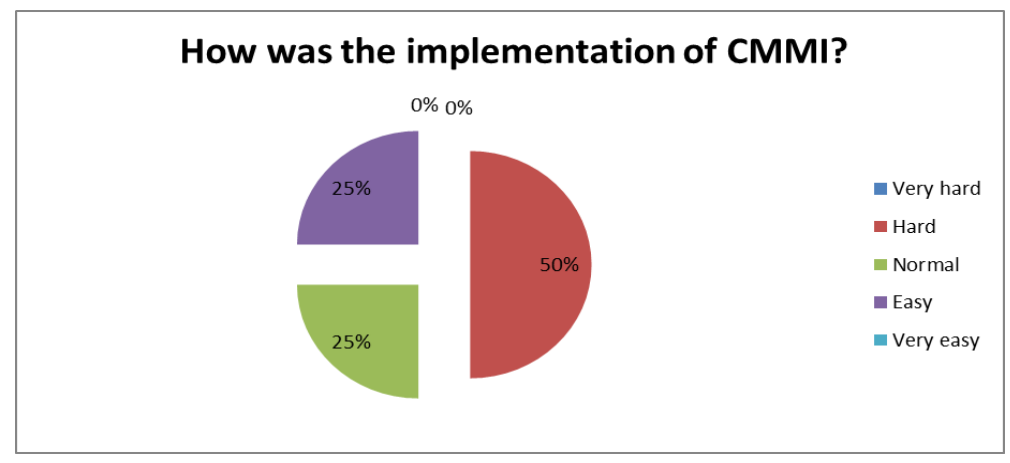

Fig. 3. Answer to question nr 1

These results show that most companies participating in the questionnaire find difficult to implement CMMI. However, these different perceptions might be related 
to business context, capacity to reduce bureaucracy when applying CMMI or turning it more complex and laborious.

Considering the current state of CMMI in the company, $75 \%$ had already implemented this methodology, but the remaining $25 \%$ are still in an implementing phase (Fig. 4).

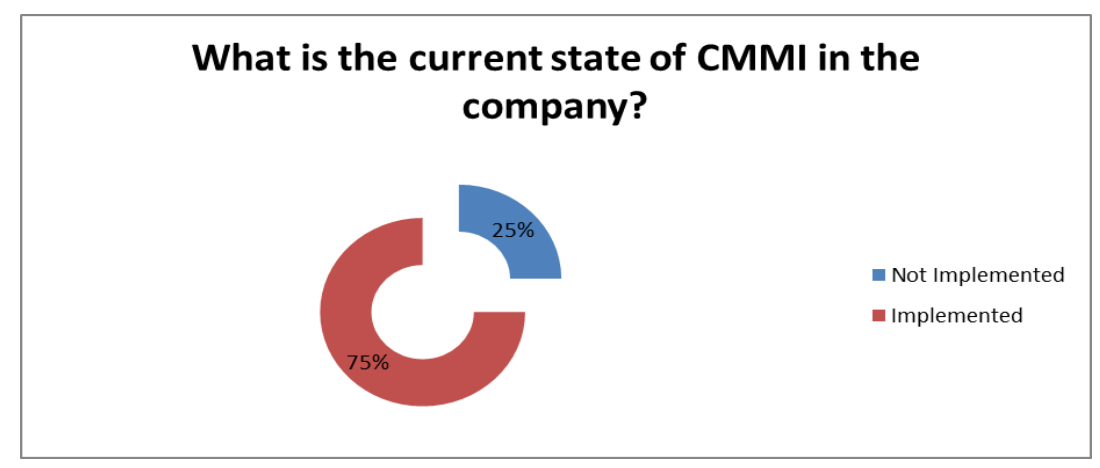

Fig. 4. Answer to question $n r 2$

Regarding the achieved maturity level, $50 \%$ of the companies present level 2 and the remaining 50\%, level 3 (Fig. 5).

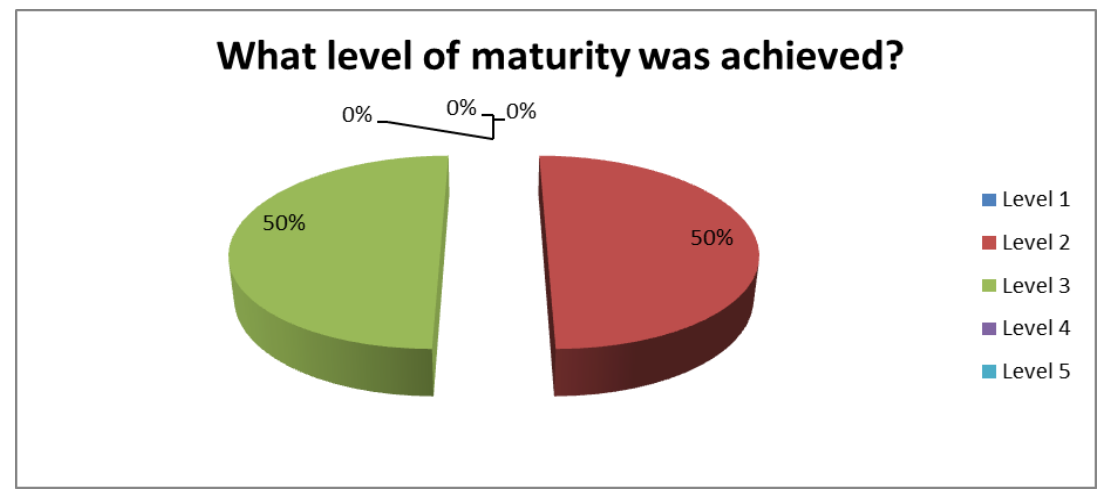

Fig. 5. Answer to question $\mathrm{nr} 3$

These results meet the available information in SEI, confirming that the most certified levels are level 2 and 3. So there is a consistency between information and results.

Considering the benefits of CMMI, results show that the highest advantage $(75 \%)$ is related to processes control and the lowest one (25\%) is centred on execution (Fig. $6)$. 


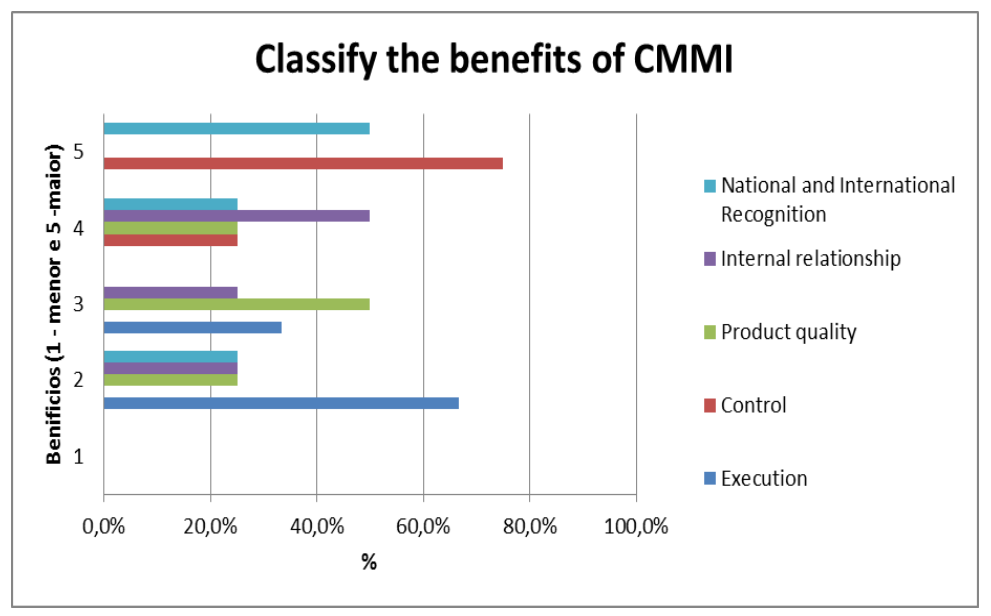

Fig. 6. Answer to question nr 4

Once more, these results meet the answers given to the previous questionnaire and considering the Northern company employees: bureaucracy regarding execution appears as an aspect to improve in this methodology.

Classifying the disadvantages of CMMI, 75\% choose the answer "Lack of involvement of employers and employees" (see Fig. 7).

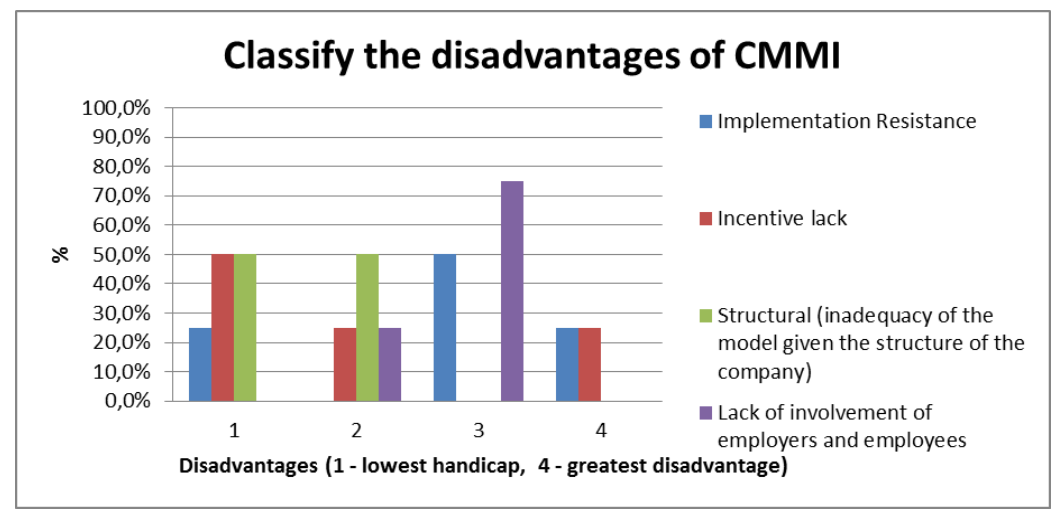

Fig. 7. Answer to question $\mathrm{nr} 5$

These results show a decreasing interest of employers affecting, consequently, the employees. This perception leads to the need on CMMI training to show the advantages of its use, turning the developed work easier. 


\subsection{Obstacles to CMM Implementation}

Analysing the previous processes and facing the answers to the applied questionnaires, we can see that all the processes involve a great complexity of tasks, leading to the need a higher number of resources to start a new project.

Here are some points that led to an ineffective implementation of the project:

- Process applied in just one department of the factory;

- Only dedicated to software;

- Very bureaucratic procedures (a lot of time spent filling in documents);

- Few new projects;

- Not applied to old projects (two different processes coexisting).

\subsection{Reimplementation of CMMI Methodology}

Taking into account the first and the second phases of the method, we started the third phase. Recognizing that the maturity methodology of the processes leads the company to its application, made us prepare a group of activities (Fig. 8). This plan of activities, accomplished with the responsible for the department under study, aimed to outline the goals to be achieved in this project, as we can see in Fig. 8 (planned tasks designed to achieve CMMI level 2).

\begin{tabular}{|c|}
\hline - Project:Re_Implement Staged Representation CMMI_Level2 "Managed" \\
\hline CMMI_Level2 managed Kick off - CDQ0302 \\
\hline Define Test System Process Flow \\
\hline Define Process Roles \\
\hline Process Policy based $C D Q 0302$ and $C M M M \mid l e v e l 2$ \\
\hline † CMMI Project TEF7 Tracking \\
\hline † CMMI Senior Manager Tracking Meetings \\
\hline † CM - Configuration Management \\
\hline † PP - Project Planning \\
\hline † PMC - Project Monitoring and Control \\
\hline † SESAM - CM\&PP\&PMC \\
\hline$\Phi$ MA - Measurement and Analysis \\
\hline$\Phi$ RM- Requirements Management \\
\hline$\Phi$ SAM- Supplier Agreement Management \\
\hline I PPQA- Process and Product Quality Assurance \\
\hline Roll out phase Pilot Projects " \\
\hline \pm SESAM - All KPA \\
\hline Final Review at BrgPITEF7 "Audit Gap" "guests CMMM experts" \\
\hline Improvements "Close Gap" \\
\hline SCAMPI B Decision\&date \\
\hline Final Assement based "SCAMPI B" Supported by SEl auditors members. \\
\hline
\end{tabular}

Fig. 8. Activities schedule

\section{Conclusions and Future Research}

In this study, we questioned about the methods used when implementing CMM. We decided to check these methodologies in a technical department of a company in the 
North of Portugal. Thus, through questionnaires, we collected perceptions of the company employees, as well as companies certified by SEI in Portugal.

In an attempt to relate affinities between the questionnaires and the work performed by the company, we conducted a general discussion in order to understand the aspects to improve in the implementation of this process.

The results obtained in the questionnaires corroborate the information provided by SEI, already developed in the literature review, because all participants questioned recognized the methodology presented by SEI as a great benefit to the products developed.

According to the results for the company employees, we found that the lack of standard documentation and processes, constitute an obstacle to the promotion of $\mathrm{CMM}$, forcing the creativity of each employee. Furthermore, accumulation of excess labor and paperwork, were some of the aspects considered disadvantageous. This handicap was also pointed out by the companies certified by SEI.

These companies perceive CMMI as a way to better control processes, but consider this approach difficult to implement. They add the disinterest of the employer as a negative factor to a successful implementation.

Based on these perceptions of CMM and CMMI, we tried to take advantage of the positive aspects highlighted and respond to the negative aspects, in order to facilitate the use of CMM, through the reimplementation of CMMI.

In this sense and taking into account that the business environment should be highlighted, we started our project with a survey of the situation in which the company was.

The analysis of the questionnaires led us to consider the bureaucracy as the main constraint to the success of this methodology. After reviewing our procedures and templates the reimplementation process continued by simplifying them. For example, we have created cost of equipment and materials tables, which improved the quotation process. Thus, we addressed the needs presented by employees and enterprises, decreasing the time spent in the processes, the accumulation of work, and also making the processes less bureaucratic.

By creating standard processes, we also contribute for greater processes control, which will lead to more successful work.

With these aspects that we think can improve the implementation of CMMI, we reduced the possibility of processes diversity, where each employee acts the way he considers best, preventing the monitoring and execution of the processes.

In an attempt to motivate and engage the employer in this methodology, we did regular presentations about the changes made, so that they were informed about all the steps done and approve them.

With these results we tried to respond to the research questions of this study. For the existing processes, we found that each employee had their own processes management documents. Despite projects key points were observed, there was no standard, making the interpretation of each project by employees who are not involved difficult.

With regard to flowcharts, this study confirmed that they are good work instruments. With them we can easily describe a process and through analysis we can find problems or improvements. 
As for the CMMI, we found that when not implemented with the cooperation of all, this is usually abandoned due to its bureaucracy. Therefore, the great challenge for the reimplementation of CMMI was, and we believe it generally is, creating support tools to facilitate the work of the employees.

The workflow of the department is achieved through the experience of those involved in projects.

Best practices for managing projects include the creation of standards that allow people not to repeat unnecessary work. In addition, creating shared and systematic processes causes people to have the same knowledge of the project, leading to the reduction of possible errors.

As usually, some strengths and weaknesses are pointed out.

The study of the entire process for a department was one of the positive aspects that allowed understanding its operation in a complete and clear way. Moreover, the finding of solutions to meet the satisfaction of the company and its employees, without reducing the customers' requirements, became an achieved challenge.

However, the search for solutions that pleased the whole organization was one of the limitations of this study. Long time was spent in the approval process for all project phases. Despite not having achieved all objectives yet, given that it is a continuous process of constant improvement, the results achieved so far point out to a successful future.

In the future, we would like to improve other key processes of CMMI methodology to achieve higher levels of maturity. Therefore, it becomes imperative to do more research on appropriate strategies necessary for the welfare of the employees of a company, when carrying out their work, viewing CMMI as a facilitator. Appropriate documentation, processes and methodologies will make workers more confident, which will be reflected in high performance.

\section{References}

1. Santos, R.P., Oliveira, K.M., Silva, W.P.: Evaluating the Service Quality of Software Providers Appraised in CMM/CMMI. Software Quality Journal 17(3), 283--301 (2009)

2. Wangenheim, C.G., Silva, D.A., Buglione, L., Scheidt, R., Prikladnicki, R.: Best Practice Fusion of CMMI-DEV v1.2 (PP, PMC, SAM) and PMBOK 2008. Information and Software Technology 52(7), 749--757 (2010)

3. SEI: Software Engineering Institute, http://www.sei.cmu.edu.

4. Sun, Y., Liu, X.: Business-oriented Software Process Improvement Based on CMMI Using QFD. Information and Software Technology 52(1), 79--91 (2010)

5. Staples, M., Niazi, M., Jeffery, R., Abrahams, A., Byatt, P., Murphy, R.: An Exploratory Study of Why Organization Do Not Adopt CMMI. The Journal of System and Software 80, 883--895 (2007)

6. Huang, S.J., Han, W.M.: Selection Priority of Process Areas Based on CMMI Continuous Representation. Information \& Management 43(3), 297--307 (2006)

7. Nandyal, R.: CMMI - A Framework for Building World-class Software and Systems Enterprises. Tata Mcgraw-Hill Publishing Co. Ltd (2004)

8. Saunders, M., Lewis, P., Thornhill, A.: Research Methods for Business Students, Fifth edition, Pearson Education (2009) 